\title{
MicroRNA-101 inhibits cell progression and increases paclitaxel sensitivity by suppressing MCL-1 expression in human triple- negative breast cancer
}

\author{
Xiaoping Liu ${ }^{1, *}$, Hailin Tang ${ }^{1, *}$, Jianping Chen ${ }^{2}$, Cailu Song ${ }^{1}$, Lu Yang ${ }^{1}$, Peng Liu ${ }^{1}$, \\ Neng Wang ${ }^{2}$, Xinhua Xie ${ }^{1}$, Xiaoti Lin ${ }^{1}$ and Xiaoming Xie ${ }^{1}$ \\ ${ }^{1}$ Department of Breast Oncology, Sun Yat-Sen University Cancer Center, State Key Laboratory of Oncology in South China, \\ Collaborative Innovation Center for Cancer Medicine, Guangzhou, Guangdong, China \\ 2 School of Chinese Medicine, The University of Hong Kong, Hong Kong \\ * These authors have contributed equally to this work \\ Correspondence to: Xiaoming Xie, email: xiexm@sysucc.org.cn \\ Keywords: miR-101, triple-negative breast cancer, paclitaxel, sensitivity, MCL-1 \\ Received: February 28, $2015 \quad$ Accepted: April 20, $2015 \quad$ Published: May 08, 2015
}

This is an open-access article distributed under the terms of the Creative Commons Attribution License, which permits unrestricted use, distribution, and reproduction in any medium, provided the original author and source are credited.

\section{ABSTRACT}

Triple-negative breast cancer is the most aggressive breast cancer subtype. The aim of our study was to investigate the functional role of both miR-101 and MCL-1 in the sensitivity of human triple-negative breast cancer (TNBC) to paclitaxel. We found that the expression of miR-101 was strongly decreased in triple-negative breast cancer tissues and cell lines. The expression of miR-101 was not associated with clinical stage or lymph node infiltration in TNBC. Ectopic overexpression of miR101 inhibit growth and induced apoptosis in vitro and suppressed tumorigenicity in vivo. MCL-1 was significantly overexpressed in most of the TNBC tissues and cell lines. Luciferase assay results confirmed MCL-1 as a direct target gene of miR-101. MiR-101 inhibited MCL-1 expression in TNBC cells and transplanted tumors. There was a negative correlation between the level of expression of miR-101 and MCL-1 in TNBC tissues. Suppression of MCL-1 enhanced the sensitivity of MDA-MB-435 cells to paclitaxel. Furthermore, miR-101 increased paclitaxel sensitivity by inhibiting MCL-1 expression. Our findings provide significant insight into the molecular mechanisms of TNBC carcinogenesis and may have clinical relevance for the development of novel, targeted therapies for TNBC.

\section{INTRODUCTION}

Breast cancer, the most common malignancy in women, is a heterogeneous disease with substantial diversity in histological and molecular characteristics that require specialized therapeutic interventions [1]. Most cases are classified as 'sporadic' breast carcinoma caused by genetic changes that occur over time [2], and only a small percentage $(5-10 \%)$ of cases are of hereditary origin. The estrogen receptor (ER), the progesterone receptor (PR) and human epidermal growth factor receptor 2 (HER2) are the molecular biomarkers currently used in routine clinical practice to help make treatment decisions for breast cancer [3]. Triple-negative breast cancer (TNBC), which was named for the absence of ER, PR, and HER2 expression, is the most aggressive breast cancer subtype. TNBC has a high propensity for metastasis and a poor prognosis [4]. Current treatment modalities for TNBC are limited to surgery, radiation, and systemic chemotherapy due to the lack of more specific therapeutic targets. However, patients often experience early relapse from distant tumor metastasis even if they initially respond well to the treatments. Over the past few decades, tremendous effort has been expended in the search for a molecular targeted therapy for TNBC with limited success [5].

MicroRNAs (miRNAs) are small, non-coding, endogenous RNA molecules involved in gene regulation that are located in introns of protein-coding genes, introns of non-coding genes, or exons of non-coding genes. These small (18-25 nucleotides long) non-coding RNAs function as post-transcriptional regulators of gene 
expression by binding to the 3' untranslated region (UTR) of target mRNAs and promoting mRNA degradation or translational repression[6]. Several studies demonstrated that miRNAs can inhibit the expression of oncogenes and tumor suppressors [7].

Furthermore, several miRNAs that play a crucial role in TNBC biology have been identified, and these miRNAs may have therapeutic implications. The causal involvement of microRNAs in breast cancer and the possible use of these small non-coding RNA molecules as biomarkers have been extensively studied, and those studies have generated promising results. Utilizing miRNAs as a therapeutic tool might be an innovative treatment approach, especially for tumor subgroups, such as TNBC, which cannot be treated with efficient and specific therapies [8]. In breast cancer, miRNA expression profiling using microarray technology, combined with some histopathological features, such as ER, PR and HER2 status, has been established as a useful tool for classifying tumors [9]. MicroRNA-101 (miR-101) expression is negatively associated with tumor growth and blood vessel formation in several solid epithelial cancers, including breast cancer. Researchers have confirmed that miR-101 acts as a tumor suppressor in gliomas [10]. The expression of miR-101 was decreased in human breast cancer tissues and inhibited cellular proliferation as well as invasiveness by targeting Stmn1 [11]. MAGI-2 suppression by miR-101 reduces PTEN activity, leading to Akt activation in MCF-7 breast cancer cells [12]. However, the role of miR-101 in TNBC remains elusive.

Myeloid cell leukemia 1 (MCL-1), a pro-survival member of the Bcl-2 (B-cell CLL/lymphoma 2) family, has been associated with the aberrant expression of prosurvival Bcl-2 family proteins and tumorigenesis as well as resistance to chemotherapies [13]. Previous studies have demonstrated that several miRNAs induce apoptosis by targeting MCL-1 in nasopharyngeal carcinoma [14], acute myeloid leukemia [15] and ovarian cancer [16]. Our previous study showed that MCL-1 could be targeted with miR-26a in breast cancer [17]. Although studies have shown that MCL-1 is a target of miR-101 in lung cancer [18] and endometrial cancer cells [19], the roles of MCL-1 and miR-101 in drug sensitivity have not been identified.

The goal of the present study was to identify "druggable" targets for TNBC to develop new treatment options. In this study, we analyzed the expression of miR-101 by using a triple-negative breast cancer tissue microarray. Previous investigations led us to study MCL1, a putative target of miR-101. After demonstrating the mechanism of miR-101 in in vitro and in vivo models, we hypothesized that miR-101 could be involved in the pathogenesis of breast cancer. In this study, miR-101 was considered a potential therapeutic target for TNBC.

\section{RESULTS}

\section{Expression of miR-101 is decreased in TNBC cell lines and tissues}

The miR-101 expression was decreased in seven of the eight breast cancer cell lines (BT-483, T47D, MCF7, SKBR3, BT-474, MDA-MB-435, MDA-MB-231, and MDA-MB-468) compared to the normal human mammary epithelial cell line MCF-10A (Figure 1A). These results indicated that miR-101 had lower expression in basallike cell lines compared to luminal cell lines. qRT-PCR revealed a decrease in miR-101 expression in 16 of 22 TNBC samples (72.7\%) (Figure 1B). Then, using ISH, we found that miR-101 expression was decreased in 56 of 86 samples (65.1\%) (Figure 1C). No significant correlations between miR-101 expression and age or tumor size were found (Table 2).

\section{MiR-101 suppresses the proliferation, apoptosis and tumorigenic capacity of TNBC cells}

To explore the functional effects of miR-101 in TNBC cells, we performed an MTT assay, flow cytometry analysis and JC-1 staining in MDA-MB-435 and MDAMB-468 cells. As shown in Figure 2A, the rate of cell survival was considerably lower for cells transfected with miR-101 mimics compared to the respective controls. By contrast, the inhibition of miR-101 by miR-101LNA significantly increased cell survival compared to the control (Figure 2A). To assess whether this effect is mediated through the induction of cell apoptosis, flow cytometry analysis and JC-1 staining were performed. The rate of apoptosis in MDA-MB-435 cells was increased following transfection with miR-101 mimics. Meanwhile, the inhibition of miR-101 suppressed cell apoptosis in MDA-MB-435 cells (Figure 2C). We found that the overexpression of miR-101 resulted in reduced MMP and increased green fluorescence in MDA-MB-435 cells (Figure 2D). Consistent with the in vitro results, the in vivo growth rate of MDA-MB-435 cells transfected with miR-101 mimics was significantly slower than the growth rate of the controls, while the miR-101-LNA group demonstrated a faster growth rate (Figure 2E). These observations provide strong evidence that the overexpression of miR-101 significantly suppresses the growth of TNBC cells in vitro and in vivo.

\section{Transfection of miR-101 sensitizes TNBC cells to paclitaxel by inducing apoptosis}

In this study, ectopic overexpression of miR-101 increased paclitaxel sensitivity, whereas the inhibition 
Table 1: Clinicopathologic characteristics of patients

\begin{tabular}{|l|l|l|}
\hline \multirow{2}{*}{ Characteristics } & Cohort 1 & Cohort 2 \\
\cline { 2 - 3 } & TNBC $(n=22)$ & TNBC $(n=86)$ \\
\hline Age (mean \pm standard deviation) & $47.8 \pm 14.5$ & $48.5 \pm 11.2$ \\
\hline Tumor size $(\mathrm{cm})$ & $6.8 \pm 1.4$ & $6.3 \pm 1.1$ \\
\hline Stage & & 61 \\
\hline I-II & 15 & 25 \\
\hline III- IV & 7 & \\
\hline Lymph node & & 41 \\
\hline Not infiltrated & 10 & 45 \\
\hline Infiltrated & 12 & \\
\hline
\end{tabular}

of miR-101 decreased paclitaxel sensitivity in MDAMB-435 cells (Figure 3A). Our results showed that enhanced expression of miR-101 caused a significant reduction in MMP, an increase in green fluorescence and an increase in the rate of apoptosis in MDA-MB-435 cells after paclitaxel treatment (Figure $3 \mathrm{~B}$ and $3 \mathrm{C}$ ). To further confirm these results, the levels of apoptotic markers were detected in transfected MDA-MB-435 cells by Western blot analysis after treatment with paclitaxel. First, we detected the effect of paclitaxel on apoptosis in MDAMB-435 cells. Increasing doses of paclitaxel enhanced the expression of cleaved caspase-3 and PARP (Figure 3D).
Western blot analysis showed that the overexpression of miR-101 significantly increased the expression of cleaved caspase-3 and PARP (Figure 3E).

\section{MCL-1 is a target of miR-101 in breast cancer cells}

TargetScan was used to help identify miR-101 targets in human TNBC. Among the candidate target genes, the algorithm predicted MCL-1 as a target (Figure 4A). The miR-101 mimics, but not miR-ctr, specifically

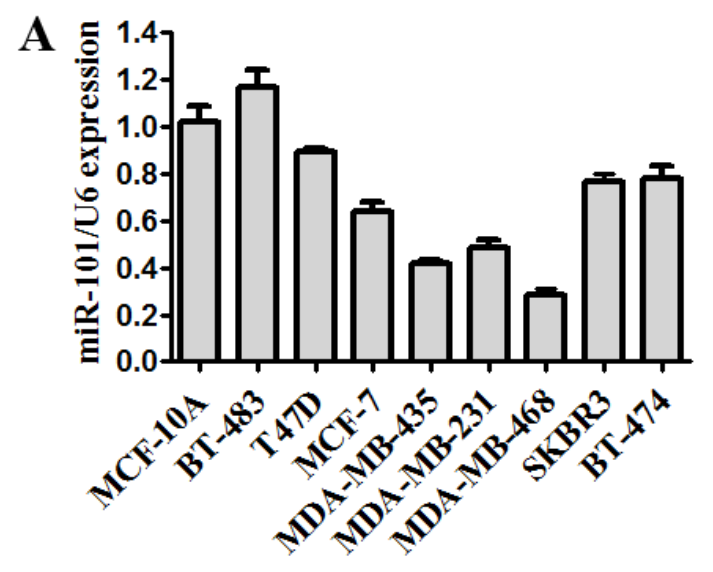

C

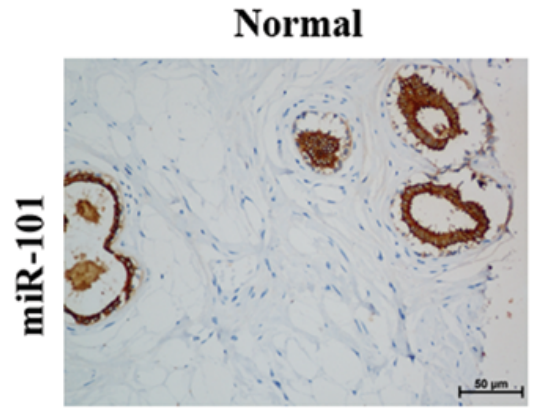

B

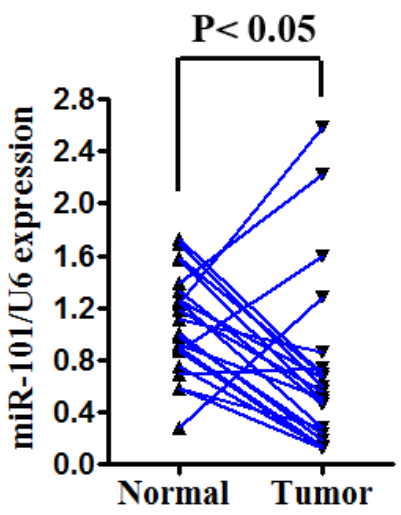

Figure 1: Expression of miR-101 is decreased in TNBC. A. miR-101 expression was determined by quantitative RT-PCR in one normal mammary cell line, five tumor cell lines with a luminal transcriptional profile and three tumor cell lines with a basal-like transcriptional profile. miR-101 expression was normalized using U6 RNA expression. Error bars represent standard deviations (SD) for three replicates in one experiment. B. miR-101 expression in 22 paired TNBC specimens and the corresponding paired normal adjacent tissues are shown in a column analysis. C. Representative images of miR-101 expression as determined by ISH. 
A

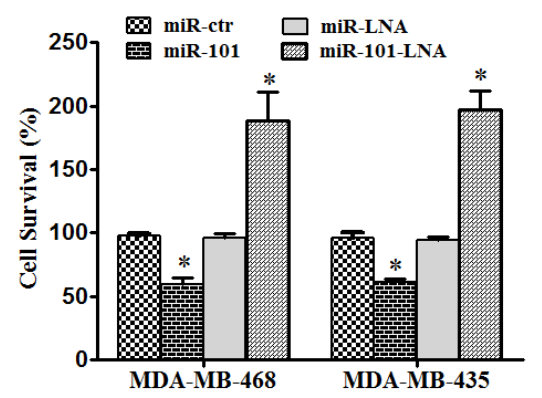

C

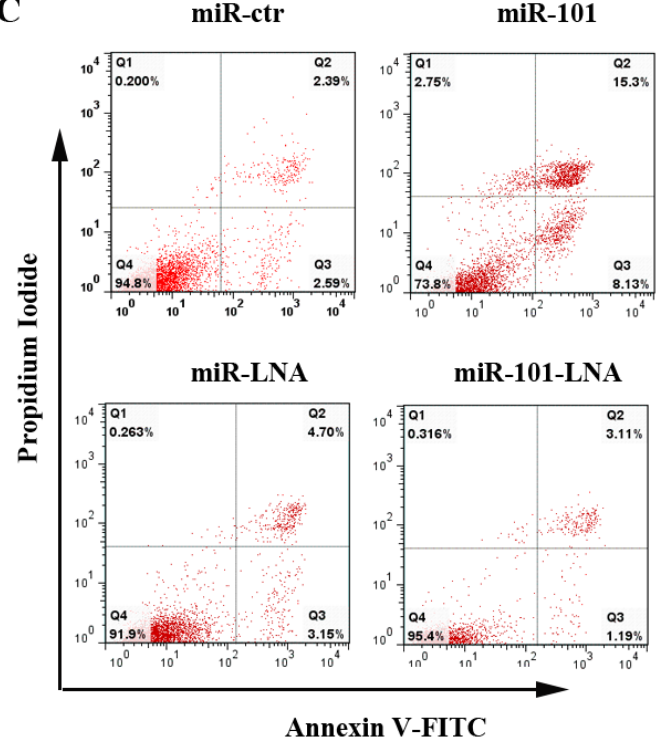

$\mathbf{E}$

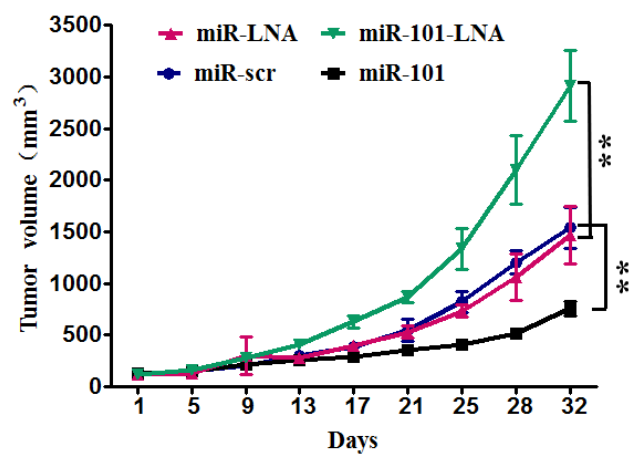

B

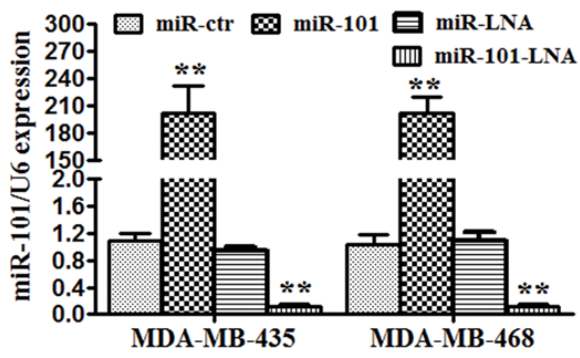

D

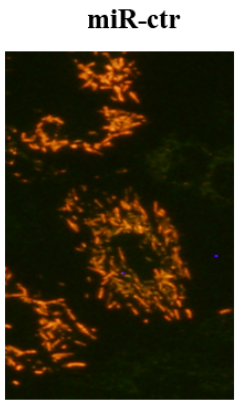

miR-101

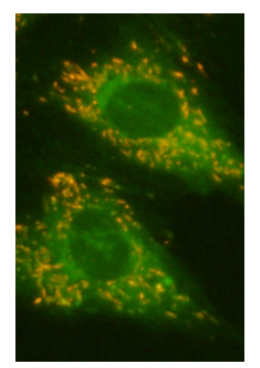

miR-LNA

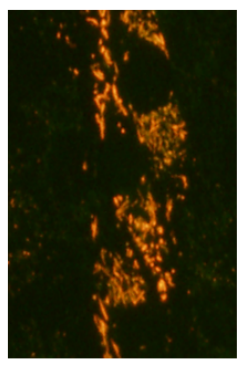

miR-101-LNA

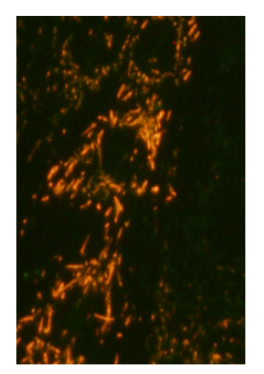

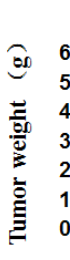
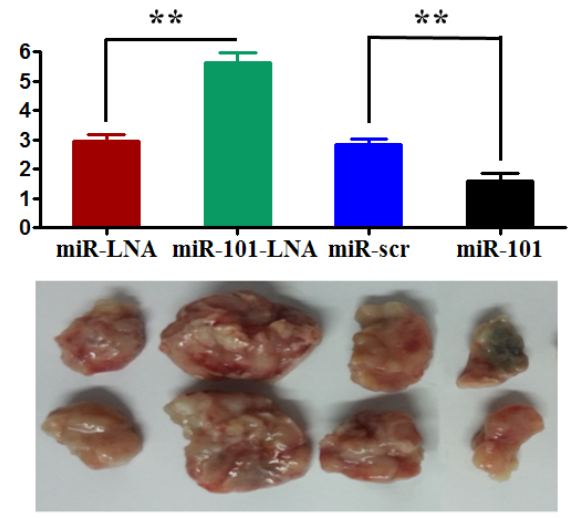

Figure 2: MiR-101 suppresses proliferation and induces apoptosis of TNBC. A. MDA-MB-435 and MDA-MB-468 cell lines were transfected with miR-101 mimics, miR-101 inhibitors or their controls. Cell viability was determined using the MTT assay at $48 \mathrm{~h}$ post-transfection. ${ }^{*} p<0.05,{ }^{*} p<0.01$. The data represent the mean $\pm \mathrm{SD}$ of three independent experiments. B. MDA-MB-435 and MDAMB-468 cells were transfected with miR-101 mimics or scramble mimics (upper panel). The effect of transfection on the levels of miR-101 expression was determined by qRT-PCR. ** $p<0.01$ vs. control. C. Apoptosis was evaluated by analyzing Annexin V-FITC and propidium iodine staining by FACS. D. MDA-MB-435 cell lines were transfected with miR-101 mimics, miR-101 inhibitors, or control sequences. Mitochondrial membrane potential (MMP, $\Delta \psi \mathrm{m}$ ) was determined at $48 \mathrm{~h}$ post-transfection. Green indicates apoptosis. E. MDA-MB-435 cells were subcutaneously injected into nude mice. Then, the effects of intratumoral injection of $40 \mu \mathrm{L}$ of scramble, miR-101 mimic or control, or miR-101 inhibitors in PBS on tumor volume was examined. The average tumor volumes are shown $(n=5$ for both experimental groups) starting from the first injection and continuing until after the mice were killed at day 32 . After 32 days, the mice were euthanized, necropsies were performed, and the tumors were weighed. All data are shown as the mean $\pm \mathrm{SD}, * * p<0.01$. 
A
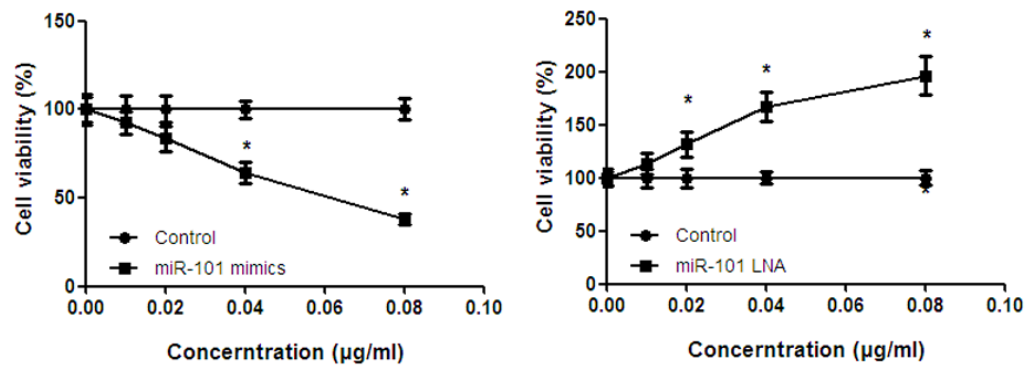

B
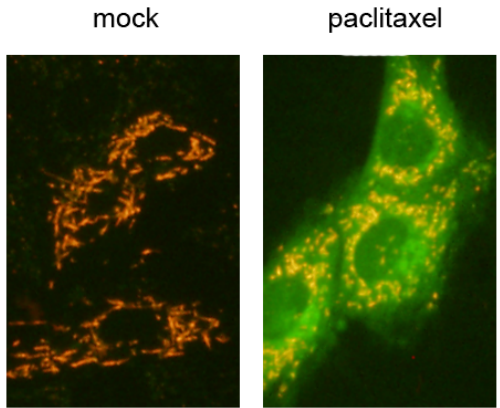

miR-ctr+paclitaxel miR-101+paclitaxel

C
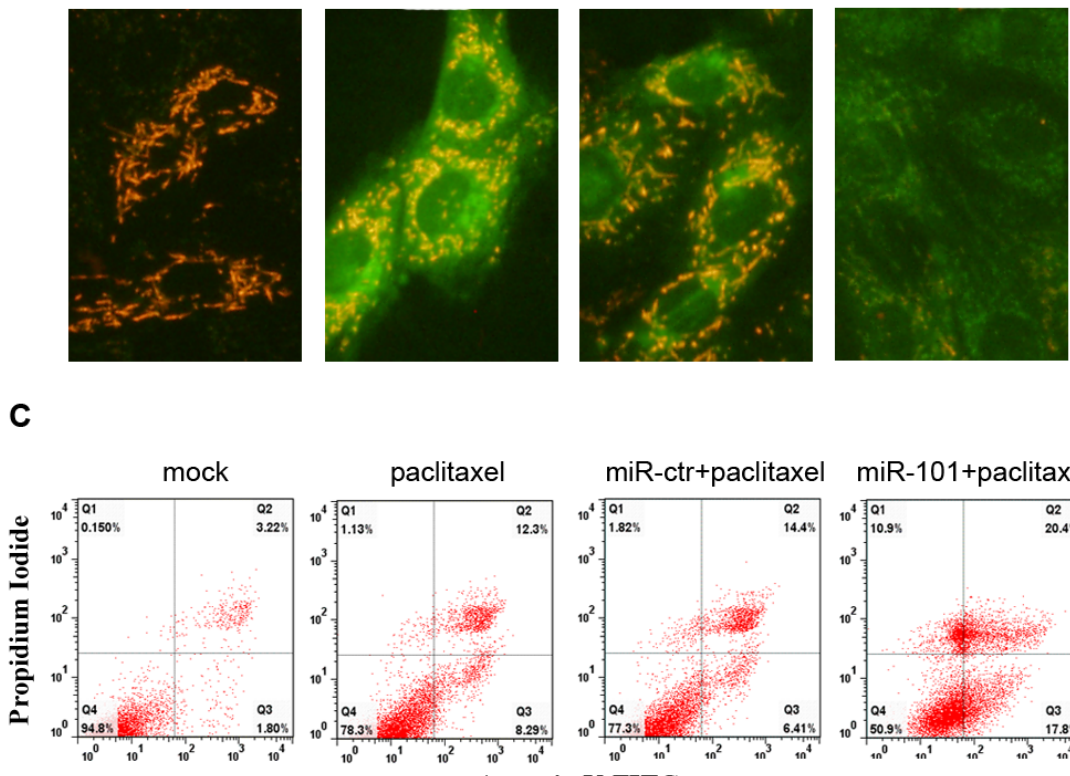

miR-ctr+paclitaxel miR-101+paclitaxel

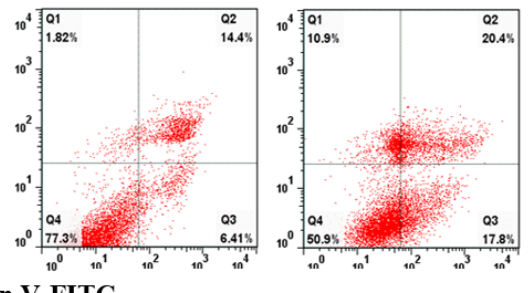

D

E

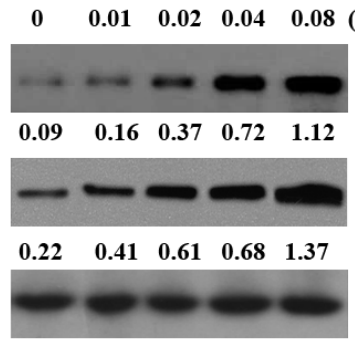

$8(\mu \mathrm{g} / \mathrm{ml})$

cleavage caspase-3

cleavage PARP

GAPDH

E

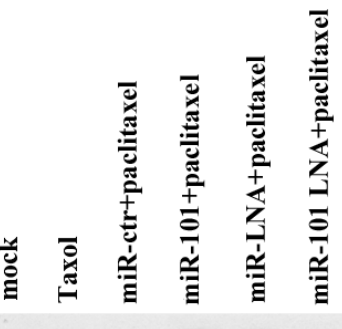

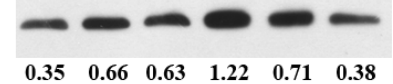

$\begin{array}{llllll}0.35 & 0.66 & 0.63 & 1.22 & 0.71 & 0.38\end{array}$

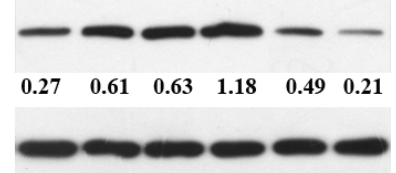

cleavage caspase- 3

cleavage PARP

GAPDH

Figure 3: Transfection of miR-101 sensitizes breast cancer cells to paclitaxel-induced apoptosis. A. The kinetics of the effect of miR-101 on breast cancer cell viability. MDA-MB-435 cells were transiently transfected with the indicated liposomal complexes, and the control group was measured for cell viability at $48 \mathrm{~h}$ post-transfection. Then, the cells were treated with different doses of paclitaxel. Data represent the mean \pm SD of three independent experiments. ${ }^{*} p<0.05$. B. MDA-MB-435 cells were transfected with paclitaxel, miR-101 mimics, miR-101 inhibitors or a combination. Mitochondrial membrane potential (MMP, $\Delta \psi \mathrm{m})$ was determined at $48 \mathrm{~h}$ posttransfection. Green indicates apoptosis. C. MDA-MB-435 cells were transfected with paclitaxel, miR-101 mimics, miR-101 inhibitors or a combination. The apoptotic cells were evaluated with Annexin V-FITC and propidium iodine staining and then analyzed by FACS. D. MDA-MB-435 cells were transfected with different doses of paclitaxel. Cleaved caspase-3 and cleaved PRAP protein levels were evaluated by Western blot. E. MDA-MB-435 cell lines were treated with paclitaxel and transfected with miR-101 mimics, miR-101 inhibitors or a combination. Cleaved caspase-3 and cleaved PRAP protein levels were evaluated by Western blot. 
Table 2: Analysis of the correlation between miR-101 expression and clinicopathological parameters in breast cancer

\begin{tabular}{|c|c|c|c|c|}
\hline \multirow{2}{*}{ Viable } & \multirow{2}{*}{ Cases } & \multicolumn{3}{|c|}{ miR-101 } \\
\hline & & Iow & high & $p$ value \\
\hline $\begin{array}{l}\text { Age (years) } \\
<50 \\
\geq 50\end{array}$ & $\begin{array}{l}43 \\
43\end{array}$ & $\begin{array}{l}28 \\
28\end{array}$ & $\begin{array}{l}15 \\
15\end{array}$ & 0.589 \\
\hline $\begin{array}{l}\text { Tumor size }(\mathrm{cm}) \\
\leq 2 \\
>2\end{array}$ & $\begin{array}{l}23 \\
63\end{array}$ & $\begin{array}{l}14 \\
42\end{array}$ & $\begin{array}{l}9 \\
21\end{array}$ & 0.400 \\
\hline $\begin{array}{l}\text { Stage } \\
\text { I-II } \\
\text { III- IV }\end{array}$ & $\begin{array}{l}61 \\
25\end{array}$ & $\begin{array}{l}34 \\
22\end{array}$ & $\begin{array}{l}27 \\
3\end{array}$ & 0.003 \\
\hline $\begin{array}{l}\text { Lymph node } \\
\text { Not infiltrated } \\
\text { Infiltrated }\end{array}$ & $\begin{array}{l}41 \\
45\end{array}$ & $\begin{array}{l}19 \\
37\end{array}$ & $\begin{array}{l}22 \\
18\end{array}$ & 0.032 \\
\hline
\end{tabular}

decreased luciferase expression of the MCL1-3'-UTRwt reporter. By contrast, no change in relative luciferase expression was observed in cells transfected with the MCL1-3'-UTR-mut reporter (Figure 4B). These results suggest that MCL-1 is a direct target of miR-101. The results of qRT-PCR and Western blot analyses showed that enhanced expression of miR-101 by miR-101 mimics in MDA-MB-435 and MDA-MB-468 cells led to the downregulation of endogenous MCL-1 mRNA and decreased protein levels. Accordingly, the inhibition of endogenous miR-101 by a miR-101 inhibitor (miR-101LNA) resulted in the upregulation of endogenous MCL-1 mRNA and protein levels compared to the negative control (Figure 4C and 4D). In transplanted tumors, the expression of MCL-1 was decreased in the miR-101-treated group (Figure 4E). The expression of MCL-1 mRNA was significantly increased in $77.2 \%$ (17/22) of tumor tissues (Figure 4F), and the protein level was overexpressed in all three TNBC cell lines (Figure 4H). Furthermore, miR101 expression was negatively correlated with MCL-1 expression in TNBC tissues $(\mathrm{R}=0.555, P<0.001$; Figure 4G).

\section{MCL-1 mediates the suppressive functions of miR-101 in TNBC cells}

The rate of cell survival was considerably lower after transfection with MCL-1 siRNA compared to respective controls in MDA-MB-468 and MDA-MB-435 cells. By contrast, the upregulation of MCL-1 by an MCL-1 overexpression vector significantly increased cell survival compared to the control (Figure 5A). In MDA-MB-468 and MDA-MB-435 cells, MCL-1 overexpression could reverse the inhibition induced by miR-101. However,
MCL-1 knockdown could erase the effect of the miR-101 inhibitor (Figure 5B). MCL-1 overexpression decreased the rate of apoptosis in MDA-MB-435 cells. miR-101 recovered the effect of MCL-1 suppression on apoptosis in MDA-MB-435 cells. MCL-1 knockdown increased the rate of apoptosis in MDA-MB-435 cells. miR-101 inhibition interrupted the induction of apoptosis in MDAMB-435 cells by MCL-1 siRNA (Figure 5C). MCL-1 knockdown resulted in reduced MMP and increased green fluorescence. Additionally, the overexpression of MCL-1 could attenuate the effect of miR-101 on MMP in MDAMB-435 cells (Figure 5D). The upregulation of MCL1 suppressed the expression of cleaved caspase- 3 and cleaved PARP, and this effect on MCL-1 was weakened by miR-101. Conversely, inhibition of MCL-1 enhanced the levels of cleaved caspase-3 and cleaved PARP, and this effect on MCL-1 was abated by miR-101 (Figure 5E).

\section{MCL-1 mediates miR-101-induced paclitaxel sensitivity in TNBC cells}

MCL-1 overexpression promotes the proliferation of MDA-MB-435 cells incubated with different doses of paclitaxel. By contrast, MCL-1 knockdown suppressed cell proliferation (Figure 6A). In paclitaxel-treated MDAMB-435 cells, miR-101 induced green fluorescence. There was still orange fluorescence after co-transfection with a MCL-1-overexpressing vector and miR-101 in MDA-MB-435 cells (Figure 6B). These results indicated that MCL-1 overexpression could attenuate the effect of miR-101 on MMP in MDA-MB-435 cells. Additionally, MCL-1 overexpression could attenuate paclitaxel or paclitaxel combined with miR-101-induced apoptosis in MDA-MB-435 cells (Figure 6C). In addition, MCL-1 
overexpression also partly suppressed apoptosis-associated cleaved caspase-3 and PARP protein levels, which were increased by paclitaxel and/or miR-101 (Figure 6D).

\section{DISCUSSION}

Emerging research has demonstrated that miRNAs play important roles in tumor development and progression, including breast cancer [7, 10, 20, 21]. While it has been reported previously that suppression of miR-101 leads to the overexpression of MCL-1 in hepatocellular carcinoma and non-small-cell lung cancer $[18,22]$, the relationship between MCL-1 and miR-101 and their biological relevance in breast cancer have not yet been fully determined, especially in TNBC. In this study, the expression of miR-101 was decreased and inversely correlated with MCL-1 expression in all basal-like cell
A

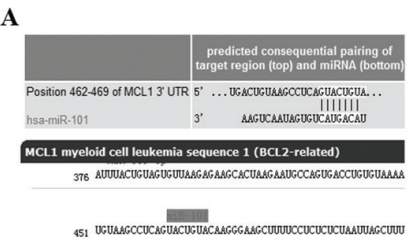

D

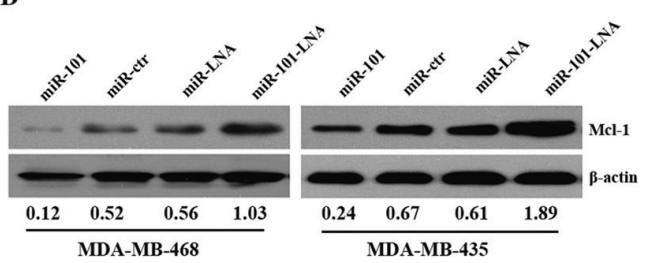

B

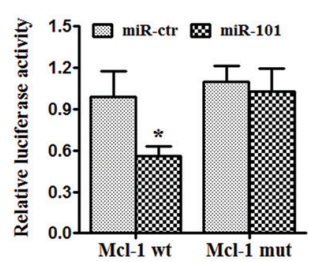

C

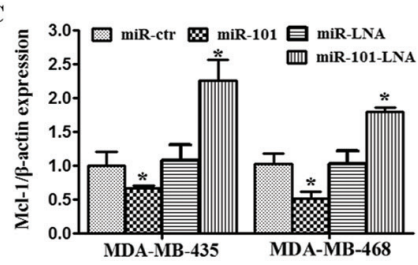

F

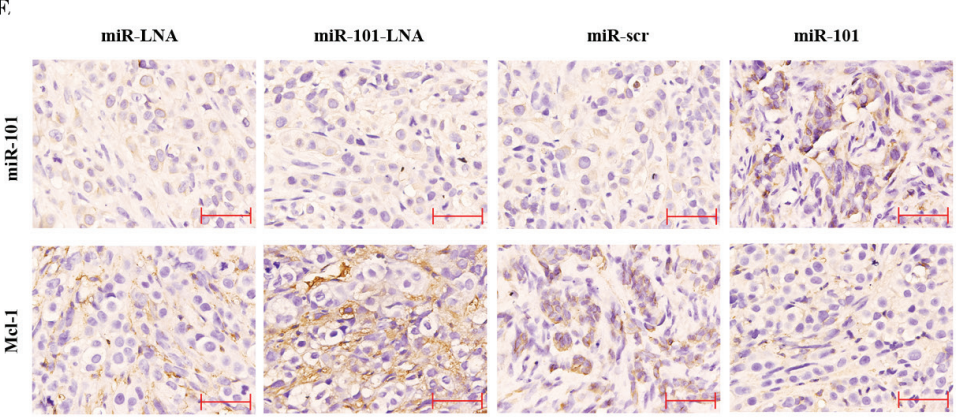

F

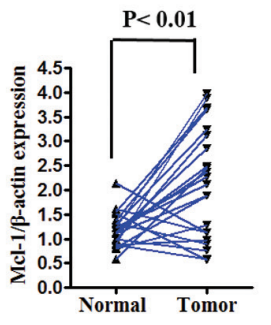

$\mathbf{G}$
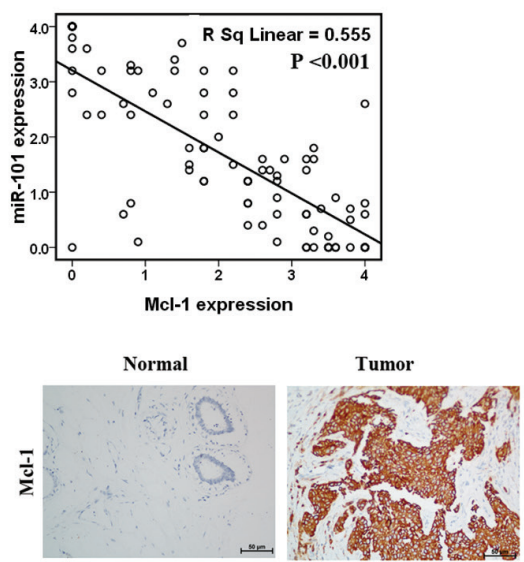

H

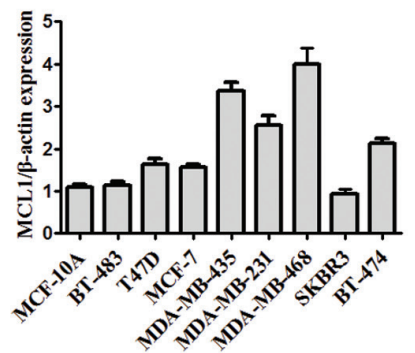

Figure 4: MiR-101 directly targets MCL-1. A. MiR-101 was predicted to bind to the MCL-1 3'-UTR using TargetScan and microRNA online software. B. A luciferase assay was performed on MDA-MB-435 cells co-transfected with miR-101 mimics, a scrambled control, miR-101 inhibitors, a control and a luciferase reporter containing MCL-1 3'-UTR (MCL-1-wt) or mutant constructs in which the five nucleotides of the miR-101 binding site were mutated (MCL-1-mut). An empty luciferase reporter construct was used as a negative control. * $p<0.05$ vs. scramble. C. MDA-MB-435 and MDA-MB-468 cell lines were transfected with miR-101 mimics, miR-101 inhibitors or their controls. The mRNA expression of MCL-1 was detected by qRT-PCR. D. The effect of miR-101 mimics or miR-101 inhibitors on the protein expression of MCL-1 was determined by Western blot in both the MDA-MB-435 and MDA-MB-468 cell lines. $\beta$-actin was used as a loading control. E. In situ hybridization was used to detect the expression of miR-101, and immunohistochemistry was used to detect the expression of MCL-1 in transplanted tumor tissues in the scramble, miR-101 mimics, control and miR-101 inhibitor groups. F. The expression of MCL-1 in 22 paired TNBC specimens and the corresponding paired normal, adjacent tissues are shown in a column analysis. G. The correlation between miR-101 and MCL-1 expression in breast cancer tissues was analyzed by comparing miRNA and mRNA expression. H. The expression of MCL-1 was determined by qRT-PCR in one normal mammary cell line, five tumor cell lines with a luminal transcriptional profile and three tumor cell lines with a basal-like transcriptional profile. miR-101 expression was normalized using U6 RNA expression. Error bars represent standard deviations (SD) for three replicates in one experiment. 
A

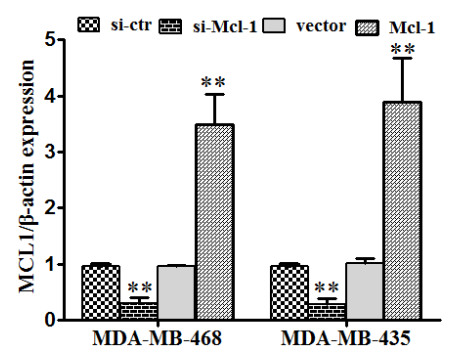

B

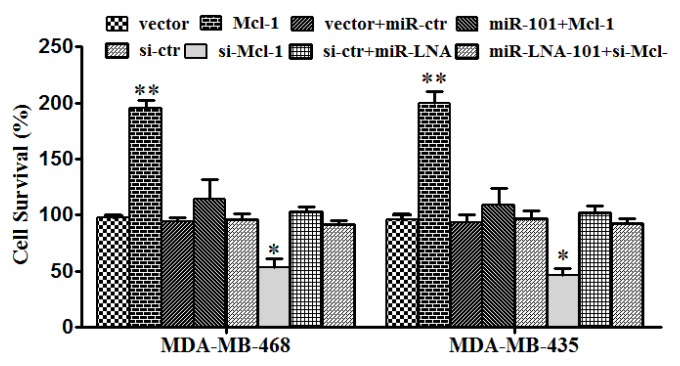

C

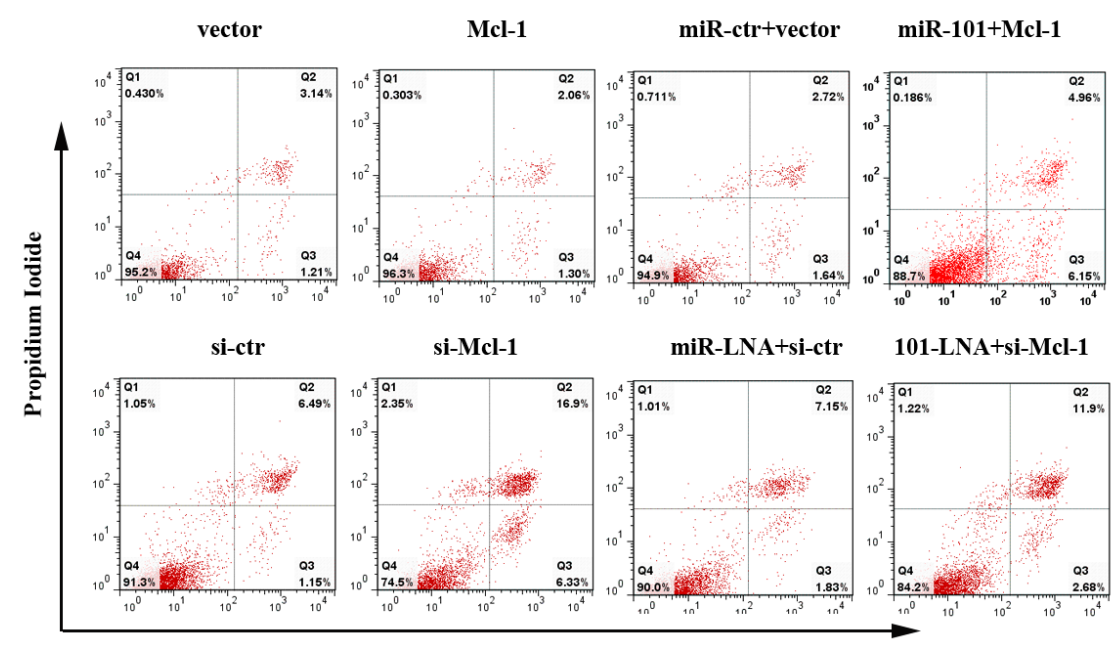

D

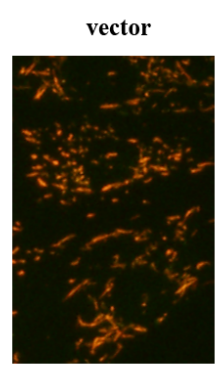

si-ctr

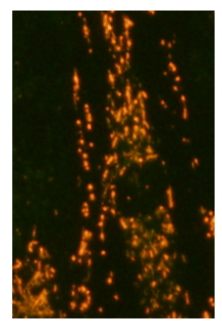

Annexin V-FITC

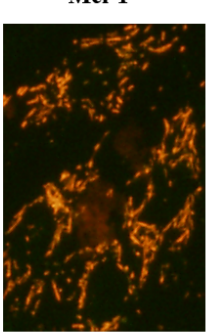

si-Mcl-1

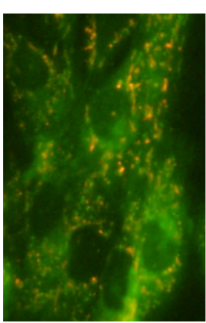

miR-ctr+vector
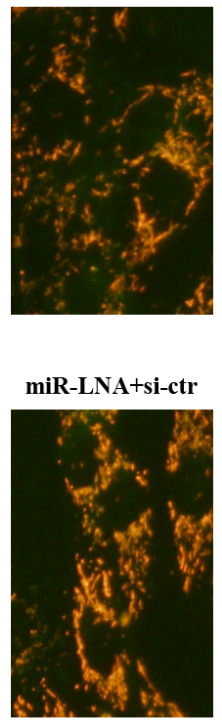

miR-101+Mcl-1

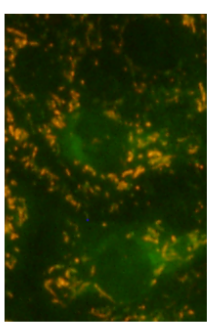

101-LNA+si-Mcl-1

\section{$\mathbf{E}$}

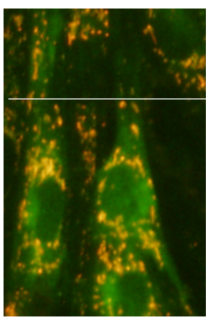

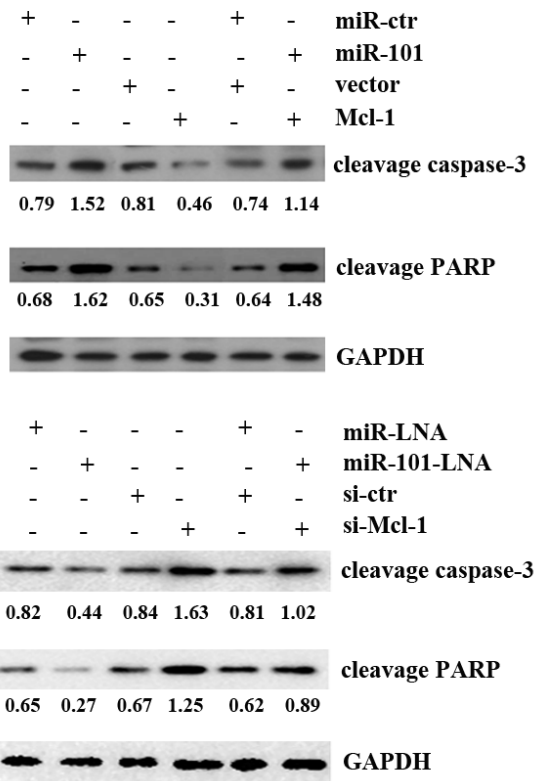

Figure 5: MiR-101 suppresses proliferation and induces apoptosis of TNBC by targeting MCL-1. A. MDA-MB-435 and MDA-MB-468 cells were transfected with an MCL-1 overexpression vector or mock vector. The effect of transfection on the levels of miR-101 expression was determined by qRT-PCR. ** $p<0.01$ vs. control. B. MDA-MB- 435 cells were transfected with miR-101 mimics, miR-101 inhibitors, a MCL-1 overexpression vector, MCL-1 siRNA or a combination. The expression of MCL-1 mRNA was detected by qRT-PCR. C. MDA-MB-435 cells were transfected with miR-101 mimics, miR-101 inhibitors, an MCL-1 overexpression vector, MCL1 siRNA or a combination. The apoptotic cells were evaluated by Annexin V-FITC and propidium iodine staining and then analyzed by FACS. D. MDA-MB-435 cells were transfected with miR-101 mimics, miR-101 inhibitors, an MCL-1 overexpression vector, MCL-1 siRNA or a combination. Mitochondrial membrane potential (MMP, $\Delta \psi \mathrm{m}$ ) was determined at $48 \mathrm{~h}$ post-transfection. Green indicates apoptosis. E. MDA-MB-435 cells were transfected with miR-101 mimics, miR-101 inhibitors, a MCL-1 overexpression vector, MCL-1 siRNA or a combination. Cleaved caspase-3 and cleaved PRAP protein expression was evaluated by Western blot. 
lines and in the majority of TNBC tissues. The results from the luciferase reporter assays confirmed that MCL-1 represents a direct target gene of miR-101 in TNBC cells.
We assessed the effect of miR-101 and MCL-1 on breast cancer growth both in vitro and in vivo. Using two TNBC cell lines, we were able to show that miR-101 suppress
A

B

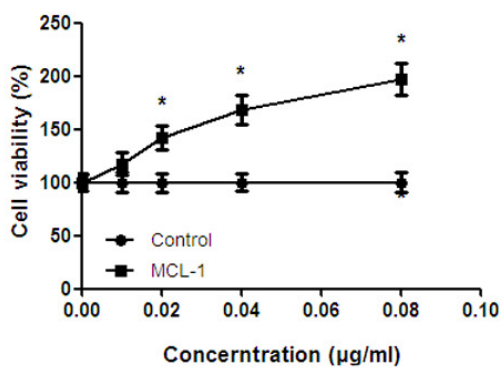

miR-NC

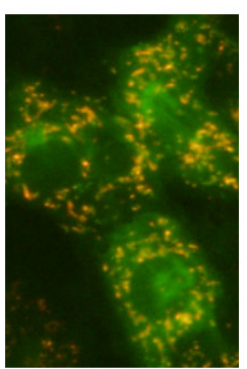

miR-101+MCL-1

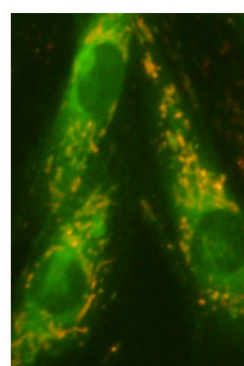

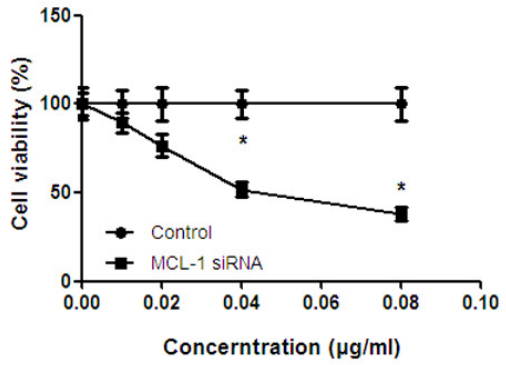

miR-NC+MCL-1
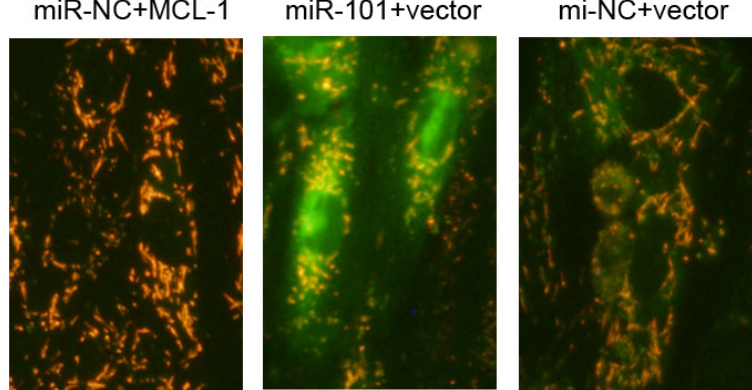

C
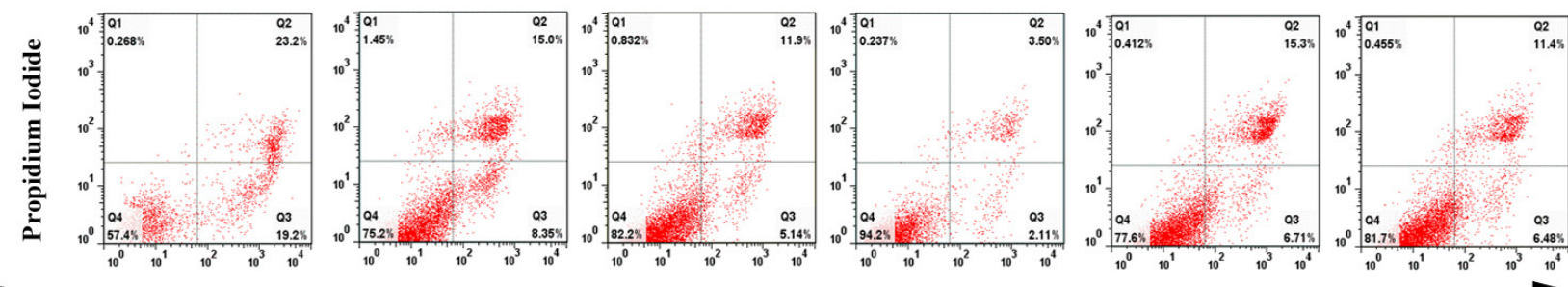

D

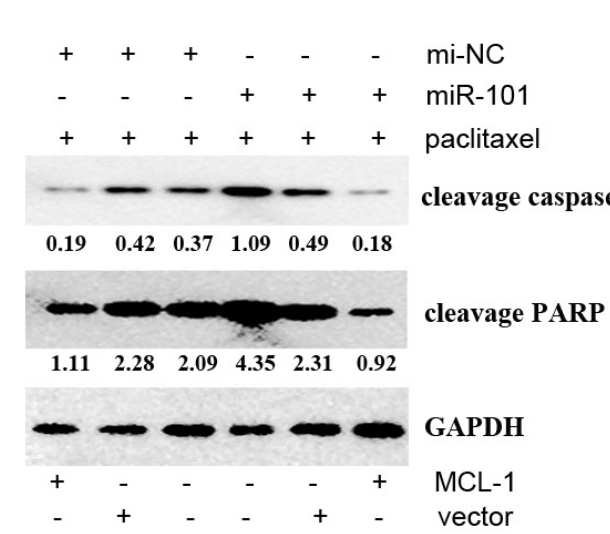

Annexin V-FITC

Figure 6: MiR-101 sensitizes TNBC cells to paclitaxel-induced apoptosis by targeting MCL-1. A. The kinetics of the effect of MCL-1 on breast cancer cell viability. MDA-MB-435 cells were transiently transfected with the indicated liposomal complexes, and the control group was measured for cell viability at $48 \mathrm{~h}$ post-transfection. Then, the cells were treated with different doses of paclitaxel. The data represent the mean $\pm \mathrm{SD}$ of three independent experiments. $* p<0.05$. B. MDA-MB-435 cells were transfected with miR-101 mimics, an MCL-1 overexpression vector or a combination. All the cells were treated with paclitaxel. Mitochondrial membrane potential (MMP, $\Delta \psi \mathrm{m})$ was determined at $48 \mathrm{~h}$ post-transfection. Green indicates apoptosis. C. MDA-MB-435 cells were transfected with miR-101 mimics, an MCL-1 overexpression vector or a combination. All the cells were treated with paclitaxel. The apoptotic cells were evaluated by Annexin V-FITC and propidium iodine staining and then analyzed by FACS. D. MDA-MB-435 cells were transfected with miR-101 mimics, an MCL-1 overexpression vector or their combined groups. All the cells were treated with paclitaxel. Cleaved caspase-3 and cleaved PRAP protein levels were evaluated by Western blot. 
the expression of MCL-1, both at the transcriptional and the post-transcriptional level. miR-101 overexpression significantly suppressed proliferation in vitro. These effects appeared to be mediated by inhibition of the MCL1 oncogene, which led to cell apoptosis. Furthermore, transfection of miR-101 mimics effectively suppressed the tumorigenicity of TNBC cells in a nude mouse model. Other studies have obtained similar results. Specifically, miR-101 suppressed tumor progression by targeting MCL1 in hepatocellular carcinoma [23] and lung cancer [24].

Studies performed by Koss B [25] indicate that endogenous MCL-1 has anti-apoptotic activity that promotes survival during BCR-ABL transformation in established BCR-ABL $(+)$ leukemia. MCL-1 mediates the inhibition of osteosarcoma pathogenesis by miR-133a [26]. MCL-1 is overexpressed in human glioblastoma, which confers a survival advantage to tumor cells. Inhibition of MCL-1 potentiates temozolomide-induced apoptosis in gliomas [27]. In our study, we were able to show that the suppression of MCL-1 significantly inhibits proliferation and induces apoptosis in vitro.

Apoptosis is a critical part of various biological processes, and it represents a regulated cellular suicide mechanism that is characterized by nuclear condensation, cell shrinkage, membrane blebbing and DNA fragmentation. Apoptosis is also involved in carcinogenesis. It has been reported that miRNAs play important roles in inducing apoptosis [28] and sensitizing tumor cells to chemotherapeutic agents [29]. For example, Wang and colleagues have demonstrated that miR-101 sensitizes human bladder cancer cells to gambogic acidinduced apoptosis by inhibiting EZH2 expression [30].

Although a number of effective options have been developed for the treatment of HER2-overexpressing diseases, TNBC remains a subtype that is difficult to treat. Taxanes are considered to be some of the most active classes of compounds that work against breast cancer [31], but a major obstacle remains for successful cancer treatment. Paclitaxel inhibits proliferation and induces apoptosis in a variety of cancers. Shi et al. demonstrated that a PARP inhibitor reduces proliferation and increases apoptosis in breast cancer cells[32]. Additional data has shown that paclitaxel can induce apoptosis in human MDA-MB-231 breast cancer cells in a caspasedependent manner. In our study, we were able to show that miR-101-mediated MCL-1 silencing sensitized TNBC cells to paclitaxel-induced apoptosis, whereas antagomir-mediated downregulation of endogenous miR-101 reversed the apoptotic effect. Future studies are needed to further elucidate the signaling pathways that control miR-101-mediated apoptosis in TNBC. In this study, we demonstrated that the overexpression of miR-101 enhanced the expression of apoptosis-related cleaved caspase 3 and PARP by targeting MCL-1 and that miR-101 could enhance the expression of paclitaxelinduced cleaved caspase 3 and PARP in TNBC cells.
These results show that miR-101 transfection increases chemotherapeutic drug-induced apoptosis in TNBC.

Our data suggest that the tumor suppressor miR-101 represses TNBC progression and sensitizes TNBC cells to paclitaxel treatment by directly targeting MCL-1. Our findings provide significant insights into the molecular mechanisms underlying breast carcinogenesis and may have relevance for the development of novel, targeted therapies for TNBC.

\section{MATERIALS AND METHODS}

\section{Cell lines and transfection}

The following cell lines were obtained from the American Type Culture Collection (Manassas, VA, USA) and were passaged in our laboratory for less than six months after the frozen aliquots were thawed: five breast cancer cell lines with a luminal transcriptional profile (BT483, T47D, MCF-7, SKBR3 and BT-474), three breast cancer cell lines with a basal-like transcriptional profile (MDA-MB-435, MDA-MB-231, and MDA-MB-468) and a normal mammary epithelial cell line (MCF-10A). Basallike breast cancer is also known as triple-negative breast cancer (TNBC) [33]. All cells were maintained according to the supplier's instructions. Before use, all cell lines were authenticated with short tandem repeat DNA profiling and were found to be free of mycoplasma infection. Plasmids, miRNAs, and small interfering RNAs (siRNAs) were transfected into the cells at the indicated concentrations using Lipofectamine 2000 (Invitrogen, Carlsbad, CA, USA) according to the manufacturer's instructions.

\section{Clinical samples}

Tissue samples from 22 cases of TNBC and the corresponding paired normal adjacent tissues, collected from September 2010 to May 2011 (Table 1), were analyzed using quantitative real-time PCR (qRT-PCR). Resected cancerous tissues and paired normal mammary tissues were immediately cut into pieces and stored in RNAlater (Ambion). The tissue microarrays consisted of 86 TNBC tissues (including the 22 collected samples). Histopathology was used to confirm TNBC in the samples collected from September 2010 to September 2012. The matched paracarcinoma tissues were used as the control samples. The specimens were stored in the Department of Specimens and Resources at Sun Yat-Sen University Cancer Center. The specimens were obtained during surgery and were formalin fixed and embedded in paraffin using standard methods. Immunohistochemistry of ER, PR and HER2 expression was performed in the Pathology Department of Sun Yat-Sen University Cancer Center. None of the patients included in the present study had 
received any chemotherapy or radiation therapy prior to the study, and their complete clinical data were available and reviewed, including age, histologic type, lymph node status, tumor size, stage, local relapse, distant metastatic relapse, ER status, PR status, and HER2 status. Histologic type was based on the TNM staging system, and the types were reclassified according to WHO classification and tumor stage (American Joint Committee on Cancer classification). Patient follow-up included a review of their records and telephone calls. The patients were grouped according to age, lymph node status, tumor size and stage. This study was approved by the Ethics Committee of Sun Yat-Sen University Cancer Center Health Authority. Written informed consent for participation in the study was obtained from all participants. The procedures for collecting and using tissues from the patients were in accordance with the ethical standards established in the Declaration of Helsinki.

\section{qRT-PCR}

Total RNA was extracted from cells with TRIzol reagent (Invitrogen, Carlsbad, USA). Reverse transcription and qRT-PCR reactions were performed with a SYBRgreen-containing PCR kit (Qiagen, Germantown, USA). The fold change was determined as $2^{-\Delta \Delta C t}$. The $C t$ is the fractional cycle number at which the fluorescence of each sample passes the fixed threshold. $\Delta \mathrm{Ct}$ was calculated by subtracting the $\mathrm{Ct}$ of snRNA U6 from the $\mathrm{Ct}$ of the miRNA of interest. $\Delta \Delta \mathrm{Ct}$ was calculated by subtracting the $\Delta \mathrm{Ct}$ of the reference sample (paired non-tumorous tissue for the surgical samples) from the $\Delta \mathrm{Ct}$ of each sample. The primers for qRT-PCR detection of MCL1 mRNA (F: TAAGGACAAAACGGGACTGG; R: CCTCTTGCCACTTGCTTTTC) were synthesized by Invitrogen. All qRT-PCR was performed with a Bio-Rad C1000 Multicolor Real-Time PCR Detection System (USA).

\section{In situ hybridization (ISH) analysis}

In situ hybridization procedures were carried out as previously described. miR-101 miRCURYTM LNA custom detection probes (Exiqon, Vedbaek, Denmark) were used for ISH. The 5'-3' sequence (enhanced with LNA) was UACAGUACUGUGAUAACUGAA with digoxigenin (DIG) at the 5' and 3' ends. Hybridization, washing, and scanning were performed according to the manufacturer's instructions. Staining intensity was scored as 0 (negative), 1+ (weak), 2+ (medium) or 3+ (strong). Low expression was defined as a staining intensity of 0 , 1,2 or 3 with $<10 \%$ of cells being stained or an intensity of 0 or 1 with $<50 \%$ of cells stained. High expression was defined as an intensity of 2 or 3 with $<10 \%$ of cells stained or an intensity of 1,2 or 3 with $<50 \%$ of cells stained.

\section{Vector construct}

An MCL-1-expressing vector was constructed. Fulllength MCL-1 cDNA was purchased from GeneCopoeia TM (USA) and was subcloned into the pcDNA3.1(+) vector. The 3'UTR of MCL-1 (pMIR-MCL-1) or the 3'UTR with mutated binding sites for miR-101 (pMIRMCL-1-mut) was synthesized by Invitrogen (China) and inserted into pMIR-REPORT, which expresses the firefly luciferase plasmid (Promega).

\section{Dual-Luciferase reporter assay and 3'UTR binding site mutagenesis}

MDA-MB-435 cells $\left(6 \times 10^{4}\right)$ were seeded in 24well plates immediately prior to transfection. The pMIRMcl1 and pMIR-Mcl1-mut constructs were transfected into MDA-MB-435 cells using Lipofectamine 2000 (Invitrogen) according to the manufacturer's instructions. The miR-101 mimic was co-transfected where indicated. Forty-eight hours post-transfection, the cells were assayed for both firefly and renilla luciferase with the dual luciferase glow assay (Promega). Transfection experiments were performed in duplicate, and each experiment was repeated at least three times.

\section{Cell proliferation assay and cell apoptosis analysis}

Cell proliferation at $48 \mathrm{~h}$ was determined using the cell proliferation reagent MTT (Roche Applied Science, Mannheim, Germany) according to the manufacturer's protocol. For cell apoptosis analysis, the cells were transfected as described in the previous section, and the apoptotic rate was detected with Annexin V/FITC staining and flow cytometry (FACSCalibur flow cytometer; BD Biosciences, Franklin Lakes, NJ, USA).

\section{Detection of mitochondrial membrane potential (MMP, $\Delta \psi \mathrm{m})$ using JC-1}

To measure the mitochondrial membrane potential $(\Delta \psi \mathrm{m}), \quad 5,5^{\prime}, 6,6^{\prime}$ '-tetrachloro-1,1',3,3'-tetraethylbenzim idazolylcarbocyanine iodide (JC-1), which is a sensitive fluorescent probe kit for $\Delta \psi \mathrm{m}$, was used on the cells (Biyuntian Biochemistry Limited Company, China). Treated or untreated cells were cultured in 24-well plates for $24 \mathrm{~h}$, washed with PBS and incubated with a working solution of JC- 1 for $20 \mathrm{~min}$ at $37^{\circ} \mathrm{C}$. Then, the cells were rinsed twice with PBS, stained with $1 \mathrm{~mL}$ of $10 \%$ DMEM medium containing $5 \mu \mathrm{mol} / \mathrm{L} \mathrm{JC}-1$, resuspended in $1 \mathrm{~mL}$ of ice-cold PBS, washed with PBS and resuspended in $500 \mu \mathrm{L}$ of PBS. The stained cells were analyzed using a 
fluorescence microscope to determine color changes in the florescence from red to green.

\section{Immunohistochemical staining}

Immunohistochemical staining was performed using an UltraSensitive S-P Kit (Maixin Biotechnology Company, Fuzhou, China). The color was developed using DAB as the chromogen. Then, the slides were counterstained with Mayer's hematoxylin and mounted for evaluation under a microscope (OLYMPUS BX-51, Osaka, Japan). Two independent pathologists who were blinded to the clinicopathological information scored the samples. Staining was scored for intensity $(1,0+; 2,1+$; $3,2+; 4,3+)$ as well as the percentage of membranous and cytoplasmic staining in malignant cells (1, 0-25\%; $2,26-50 \% ; 3,51-75 \% ; 4,76-100 \%)$. The final score was obtained by multiplying the intensity score by the score for the percentage counts. A score of $<8$ was considered to be low expression, and a score of $>8$ was considered to be high expression.

\section{Western blot}

Sodium dodecyl sulfate-polyacrylamide gel electrophoresis (SDS-PAGE) was performed on protein lysates from the cells, and the target proteins were detected with primary antibodies recognizing MCL-1 (Santa Cruz, USA), Caspase-3, Cleaved PARP and GAPDH (Cell Signaling). After incubation with the appropriate horseradish peroxidase (HRP)-conjugated secondary antibodies (Jackson ImmunoResearch), the protein bands were visualized using enhanced chemiluminescence (ECL) Western blot detection reagents and then analyzed with the Bio Image Intelligent Quantifier 1-D (Version 2.2.1, Nicon-BioImage Ltd., Japan).

\section{Human tumor xenograft model}

To investigate the antitumor effects of miR-101 in vivo, female BALB/c-nude mice (4-6 weeks old; Vital River Laboratories Animal, Beijing, China) were injected subcutaneously in the right fourth mammary gland with $5 \times 10^{6}$ MDA-MB-435-Luc cells in $100 \mu \mathrm{L}$ of PBS with a 30-gauge needle. Tumor formation was monitored by palpation, and tumor size was measured twice per week using calipers. Tumor volume was calculated using the standard formula: tumor volume $=\left(\right.$ width $^{2} \times$ length $\left.\times \pi\right) / 6$. When the tumors reached $\sim 50 \mathrm{~mm}^{3}$, the mice were noninvasively imaged using the IVIS In Vivo Imaging System (Xenogen, Alameda, CA) to confirm tumor growth. Then, the mice were randomly assigned to one of four groups ( $n=10$ mice per group): miR-LNA, miR101-LNA, miR-scramble or miR-101 mimics. All groups received intratumoral injections twice a week for three consecutive weeks. Mouse weight and tumor progression were monitored daily using the IVIS system with Living Imaging software (Xenogen). On day 32, the mice were euthanized by spinal dislocation, and the tumors and hearts were immediately harvested, weighed, and analyzed. All experiments were performed in accordance with institutional guidelines and were approved by the animal care and use committee at the University of Sun Yat-Sen University Cancer Center.

\section{Statistical analysis}

All values are expressed as the mean \pm standard error of the mean. All experiments using cell lines were repeated a minimum of 3 times. Statistical significance was reported if the $p$-value was $<0.05$ using an unpaired Student's $t$-test.

\section{ACKNOWLEDGMENTS}

This work was supported by funds from the National Natural Science Foundation of China (81472575, $81472469,81272514,81302318$, and 81301798), the Key Program of the National Natural Science Foundation of China (31030061), and the China Postdoctoral Science Foundation (2014M550447). The Science and Technology Planning Project of Guangzhou and Guangdong also provided funding for this research (2014J4100169 and 2013B060300009).

\section{DISCLOSURE OF CONFLICTS OF INTEREST}

The authors declare that they have no competing interests.

\section{REFERENCES}

1. Kurisetty VV, Lakshmanaswamy R, Damodaran C. Pathogenic and therapeutic role of miRNAs in breast cancer. Front Biosci (Landmark Ed). 2014; 19:1-11.

2. Bradbury AR, Olopade OI. Genetic susceptibility to breast cancer. Rev Endocr Metab Disord. 2007; 8:255-67.

3. Mulrane L, McGee SF, Gallagher WM, O'Connor DP. miRNA dysregulation in breast cancer. Cancer Res. 2013; 73:6554-62.

4. Foulkes WD, Smith IE, Reis-Filho JS. Triple-negative breast cancer. N Engl J Med. 2010; 363:1938-48.

5. Lee ST, Feng M, Wei Y, Li Z, Qiao Y, Guan P, Jiang X, Wong CH, Huynh K, Wang J, Li J, Karuturi KM, Tan EY, Hoon DS, Kang Y, Yu Q. Protein tyrosine phosphatase UBASH3B is overexpressed in triple-negative breast cancer and promotes invasion and metastasis. Proc Natl Acad Sci 
U S A. 2013; 110:11121-6.

6. Shukla GC, Singh J, Barik S. MicroRNAs: Processing, Maturation, Target Recognition and Regulatory Functions. Mol Cell Pharmacol. 2011; 3:83-92.

7. Blandino G, Fazi F, Donzelli S, Kedmi M, Sas-Chen A, Muti P, Strano S, Yarden Y. Tumor suppressor microRNAs: A novel non-coding alliance against cancer. FEBS Lett. 2014; 588:2639-52

8. D'Ippolito E, Iorio MV. MicroRNAs and triple negative breast cancer. Int J Mol Sci. 2013; 14:22202-20.

9. Buffa FM, Camps C, Winchester L, Snell CE, Gee HE, Sheldon H, Taylor M, Harris AL, Ragoussis J. microRNAassociated progression pathways and potential therapeutic targets identified by integrated mRNA and microRNA expression profiling in breast cancer. Cancer Res. 2011; 71:5635-45.

10. Xiaoping L, Zhibin Y, Wenjuan L, Zeyou W, Gang X, Zhaohui L, Ying Z, Minghua W, Guiyuan L. CPEB1, a histone-modified hypomethylated gene, is regulated by miR-101 and involved in cell senescence in glioma. Cell Death Dis. 2013; 4:e675.

11. Wang R, Wang HB, Hao CJ, Cui Y, Han XC, Hu Y, Li FF, Xia HF, Ma X. MiR-101 is involved in human breast carcinogenesis by targeting Stathmin1. PLoS One. 2012; 7:e46173.

12. Sachdeva M, Wu H, Ru P, Hwang L, Trieu V, Mo YY. MicroRNA-101-mediated Akt activation and estrogenindependent growth. Oncogene. 2011; 30:822-31.

13. Youle RJ, Strasser A. The BCL-2 protein family: opposing activities that mediate cell death. Nat Rev Mol Cell Biol. 2008; 9:47-59.

14. Zhang JX, Qian D, Wang FW, Liao DZ, Wei JH, Tong ZT, Fu J, Huang XX, Liao YJ, Deng HX, Zeng YX, Xie D, Mai SJ. MicroRNA-29c enhances the sensitivities of human nasopharyngeal carcinoma to cisplatin-based chemotherapy and radiotherapy. Cancer Lett. 2012; 329:91-8.

15. Lu F, Zhang J, Ji M, Li P, Du Y, Wang H, Zang S, Ma D, Sun X, Ji C. miR181b increases drug sensitivity in acute myeloid leukemia via targeting HMGB1 and Mcl-1. Int J Oncol. 2014; 45:383-92.

16. Rao YM, Shi HR, Ji M, Chen CH. MiR-106a targets Mcl1 to suppress cisplatin resistance of ovarian cancer A2780 cells. J Huazhong Univ Sci Technolog Med Sci. 2013; 33:567-72.

17. Gao J, Li L, Wu M, Liu M, Xie X, Guo J, Tang H. MiR-26a inhibits proliferation and migration of breast cancer through repression of MCL-1. PLoS One. 2013; 8:e65138.

18. Luo L, Zhang T, Liu H, Lv T, Yuan D, Yao Y, Lv Y, Song Y. MiR-101 and Mcl-1 in non-small-cell lung cancer: expression profile and clinical significance. Med Oncol. 2012; 29:1681-6.

19. Konno Y, Dong P, Xiong Y, Suzuki F, Lu J, Cai M, Watari H, Mitamura T, Hosaka M, Hanley SJ, Kudo M, Sakuragi N. MicroRNA-101 targets EZH2, MCL-1 and
FOS to suppress proliferation, invasion and stem celllike phenotype of aggressive endometrial cancer cells. Oncotarget. 2014; 5:6049-62.

20. Tessitore A, Cicciarelli G, Del Vecchio F, Gaggiano A, Verzella D, Fischietti M, Vecchiotti D, Capece D, Zazzeroni F, Alesse E. MicroRNAs in the DNA Damage/Repair Network and Cancer. Int J Genomics. 2014; 2014:820248.

21. Shah NR, Chen H. MicroRNAs in pathogenesis of breast cancer: Implications in diagnosis and treatment. World J Clin Oncol. 2014; 5:48-60.

22. Su H, Yang JR, Xu T, Huang J, Xu L, Yuan Y, Zhuang SM. MicroRNA-101, down-regulated in hepatocellular carcinoma, promotes apoptosis and suppresses tumorigenicity. Cancer Res. 2009; 69:1135-42.

23. Chatterjee M, Li K, Chen L, Maisano X, Guo Q, Gan L, Li JY. Gbx2 regulates thalamocortical axon guidance by modifying the LIM and Robo codes. Development. 2012; 139:4633-43.

24. Sdek P, Oyama K, Angelis E, Chan SS, Schenke-Layland K, MacLellan WR. Epigenetic regulation of myogenic gene expression by heterochromatin protein 1 alpha. PLoS One. 2013; 8:e58319.

25. Koss B, Morrison J, Perciavalle RM, Singh H, Rehg JE, Williams RT, Opferman JT. Requirement for antiapoptotic MCL-1 in the survival of BCR-ABL B-lineage acute lymphoblastic leukemia. Blood. 2013; 122:1587-98.

26. Ji F, Zhang H, Wang Y, Li M, Xu W, Kang Y, Wang Z, Cheng P, Tong D, Li C, Tang H. MicroRNA-133a, downregulated in osteosarcoma, suppresses proliferation and promotes apoptosis by targeting Bcl-xL and Mcl-1. Bone. 2013; 56:220-6.

27. Li RY, Chen LC, Zhang HY, Du WZ, Feng Y, Wang HB, Wen JQ, Liu X, Li XF, Sun Y, Yang DB, Jiang T, Li YL, Jiang CL. MiR-139 inhibits Mcl-1 expression and potentiates TMZ-induced apoptosis in glioma. CNS Neurosci Ther. 2013; 19:477-83.

28. Di Leva G, Garofalo M, Croce CM. MicroRNAs in cancer. Annu Rev Pathol. 2014; 9:287-314.

29. Kontos CK, Christodoulou MI, Scorilas A. Apoptosisrelated BCL2-family members: Key players in chemotherapy. Anticancer Agents Med Chem. 2014; 14:353-74.

30. Wang Y, Xiang W, Wang M, Huang T, Xiao X, Wang L, Tao D, Dong L, Zeng F, Jiang G. Methyl jasmonate sensitizes human bladder cancer cells to gambogic acidinduced apoptosis through down-regulation of EZH2 expression by miR-101. Br J Pharmacol. 2014; 171:618-35.

31. Gluck S. nab-Paclitaxel for the Treatment of Aggressive Metastatic Breast Cancer. Clin Breast Cancer. 2014; 14:221-7

32. Shi Y, Zhou F, Jiang F, Lu H, Wang J, Cheng C. PARP inhibitor reduces proliferation and increases apoptosis in breast cancer cells. Chin J Cancer Res. 2014; 26:142-7.

33. Carey LA, Perou CM, Livasy CA, Dressler LG, Cowan D, 
Conway K, Karaca G, Troester MA, Tse CK, Edmiston S, Deming SL, Geradts J, Cheang MC, Nielsen TO, Moorman

PG, Earp HS, Millikan RC. Race, breast cancer subtypes, and survival in the Carolina Breast Cancer Study. JAMA.

2006; 295:2492-502. 